"Mircea cel Batran" Naval Academy Scientific Bulletin, Volume XX - 2017 - Issue 1

Published by "Mircea cel Batran" Naval Academy Press, Romania /I The journal is indexed in: PROQUEST I

DOAJ / DRJI / JOURNAL INDEX I I2OR / SCIENCE LIBRARY INDEX / Google Scholar / Crossref / Academic Keys I ROAD Open Access I OAJI / Academic Resources / Scientific Indexing Services / SCIPIO / JIFACTOR

\title{
ELECTRICAL PROPULSION ANALYSIS FOR A PASSENGER SHIP
}

\author{
Dumitru IORGULESCU ${ }^{1}$ \\ Gheorghe SAMOILESCU ${ }^{2}$ \\ Florian TĂNASE ${ }^{2}$ \\ Nicolae BĂDĂRĂ ${ }^{2}$ \\ Raluca MATEŞ-APOSTOL ${ }^{3}$ \\ ${ }^{1}$ Engineer, Port Line Crewing Portugal; Military Technical Academy, Bucharest \\ ${ }^{2}$ Engineer Ph.D, 'Mircea cel Bătrân' Naval Academy, Constantza \\ 3 Lecturer Ph.D, 'Mircea cel Bătrân' Naval Academy, Constantza
}

\begin{abstract}
The electrical energy obtained onboard a ship is split up on the engine room on different electrical control panels. The main electrical control panels are usually divided into two, three or four sections, for a better operation of the ship. According to rules and regulations for electrical propulsion, an electrical control panel can take the unfavorable consequences in case of one section breaks down due to a fault. To avoid the usage of an expensive electrical installation, the electrical energy command system is to be split into three or four electrical control panels. In electrical propulsion regime, the electrical control panels are interconnected, resulting into a better flexibility for electrical energy generation mechanism configuration. Losing propulsion or energy maintaining station in one part of the system is going to have an impact on the remaining installations through the control system. The remaining electrical energy must maintain ship's maneuverability, stability and buoyancy. Therefore, we have analyzed the electrical propulsion components, the sequential control of propulsion engines and their limitations.
\end{abstract}

Key words: electric propulsion, electric engine, electronic apparatus, maritime electro-energetic system

\section{Introduction}

The electrical propulsion system has the following functions $[1,2,3]$ :

- to ensure the electric control of propulsion;

- to ensure that the electrical propulsion system is totally independent - every electrical equipment having two propellers and, implicative, two engines, in order to ensure the propulsion availability for each engine and independent powering, as well as the control of these two engines;

- to ensure the error management through the programmed decisions for the safety actions regarding propulsion (automatic couple reduction, alarm, engine functionality);

- to ensure the safety of the automatic propulsion system - to prevent blackouts.

The electric propulsion is powered from the 11000 $\checkmark[4,20]$ high voltage network of the vessel. The vessel is equipped with two power lines. Each line consists of an electric engine with a converter, each one being connected at the main distribution board on port and starboard sides [4]. The propulsion system is totally independent, meaning that the errors during the functioning of the external equipment do not affect the propulsion system.

A fault in the energetic of an engine (transformer, converter) or on the control system of an electric engine is able to disconnect the propulsion engine and the available couple will be of $50 \%$ of the nominal couple.

\section{The electric propulsion components}

\subsection{The transformer with cooling pump}

Each transformer is equipped with:

- two circular oil pumps (one in use and one in stand-by) for ensuring a constant flow of the oil in the transformer;

- water/oil exchanger which cools the oil through a heat exchange with the fresh water system of the vessel.

The operation of the equipment can be local or from the command room as follows:

- the selection (Normal, Stand-by) is done in the monitoring system;

- when the "Auxiliary On" command is launched, the cooling pump starts;

- When the "Auxiliary Off" command is launched, the cooling pump stops. The cooling pump also stops in case of the excitation circuit breaker is open (propulsion is stopped) for more than 30 minutes and if the main breaker is open or if the temperature of oil is below $50^{\circ} \mathrm{C}$.

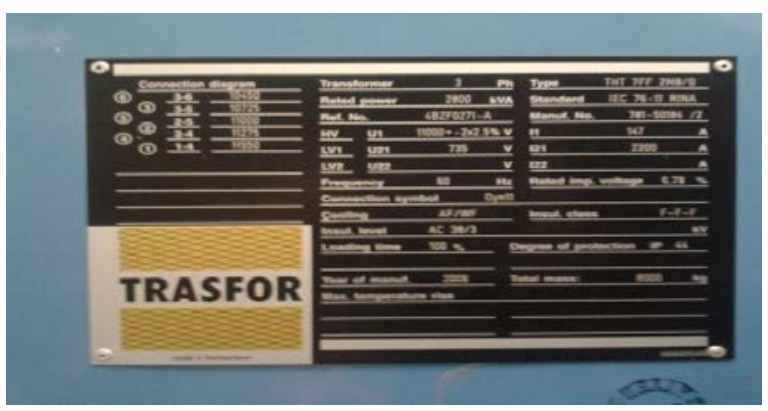

Figure 1. 


\begin{abstract}
"Mircea cel Batran" Naval Academy Scientific Bulletin, Volume XX - 2017 - Issue 1
Published by "Mircea cel Batran" Naval Academy Press, Romania /I The journal is indexed in: PROQUEST I DOAJ / DRJI / JOURNAL INDEX / I2OR / SCIENCE LIBRARY INDEX / Google Scholar / Crossref / Academic Keys I ROAD Open Access / OAJI / Academic Resources / Scientific Indexing Services / SCIPIO / JIFACTOR
\end{abstract}

Until the main circuit breaker is closed, the pump is running.

In case the electrical pump has a fault and in case for 10 seconds the flow of oil is reduced, then the pump is stopped and the stand-by one is started automatically.

\subsection{The converter with cooling pump}

Each converter is equipped with (figure 2):

- two de-ionized water circular pumps (one in use, one on stand-by) in order to ensure a constant flow in all the cooling systems;

- one heat exchanger water/water for the decks and the reactor bight: the water/water exchanger is cooling the de-ionized hot water through a heat exchange system connected to the fresh water system of the ship. The powering sequence of the pump may be considered finished when the conductivity level of the ionized water is less or equal with the normal threshold. When the stand-by pump is running, if for ten seconds it is not detected the ionized water pressure or it is detected low pressure, the propulsion engine will be shut down.

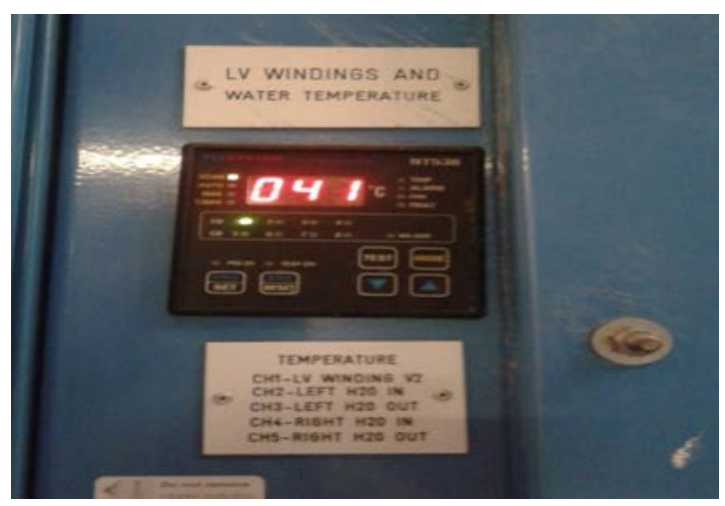

Figure 2.

\subsection{Ventilation engines}

The propulsion engine has four ventilators, each one having a two-speed engine.

When the "On" command is launched, the ventilators are turned on.

The hot air from the engine is extracted by the ventilators through the hydro coolers, through which a caloric exchange is realized with the fresh water system of the vessel, and the resulting cooled air is forced by the ventilators through the engine.

When the "Off" command is launched, the ventilators are shut off. These are also automatically shut off if the breaker of the excitation circuit is open (propulsion is stopped) for 30 minutes or if the temperature is below $10^{\circ}$ C.

In the case one or more ventilators have electrical faults, the available couple for the propulsion engine is: one ventilator $-60 \%$ of the nominal couple available; two ventilators in opposite positions $-66 \%$ of the nominal couple available.

\subsection{The installation for lifting the rotor of the propulsion engine}

Each propulsion engine is equipped with a jack lifting unit, including two pumps. Their function is to lift the rotor between -25 to $+25 \mathrm{rpm}$. When over $+25 \mathrm{rpm}$, the oil film in the installation is auto created by the rotation of the shaft and by construction. One jack lifting pump is always running for having a continuous control.

In the normal functioning, the selected pump can be stopped only by local command. The operator has to check if the mechanical block is active. In case of an electric fault, the turning on command is cancelled and shutting off command is sent by the propulsion system to the pump in normal regime, and the stand-by pump is turned on automatically.

In case of low oil pressure alarm or low flow, the stand-by pump is started automatically. The command for starting the pump in normal regime is maintained until the reparation of the oil pressure and flow.

\section{Sequential control of propulsion engine}

Each propulsion section - PEC, has a sequential procedure for controlling of own engine. The sequential control can be initialized:

- remotely: orders and information are given by pressing the On/Off buttons from the remote control board on the propulsion section by the Ethernet network. This function is active only in the case that the propulsion is controlled from the command room.

- local: orders and information are given (by pushing the On/Off buttons) from the local control panel at the propulsion section by the Ethernet network. This function is active only in case that the propulsion is controlled from the local control panel. The local control mode should be used only in emergencies.

All the conditions from the remote control system are automatically replaced in the "local command" mode when the connection with the remote control system is not functioning properly.

When the "On" button is pushed, the PEC instruction sequence consist of: closing the Machine Bridge Isolating Switch (MBIS); closing the engine breaker, closing the breaker of the excitation circuit; the excitation is stabilized by the regulator. After that the reference speed value is set from the local emitter for the reference speed in the local or remote control systems.

When the "Off" button is pressed, the PEC instruction sequence consists of: cancelation of the reference speed, cancelation of the excitation request, turning off the excitation using the breaker.

Sequential control starting may be done if the following conditions are met: the revolution device is disconnected; shaft line is free (not blocked); the lubricating is ready (with the DE and NDE 


\begin{abstract}
"Mircea cel Batran" Naval Academy Scientific Bulletin, Volume XX - 2017 - Issue 1
Published by "Mircea cel Batran" Naval Academy Press, Romania /I The journal is indexed in: PROQUEST I DOAJ / DRJI / JOURNAL INDEX / I2OR / SCIENCE LIBRARY INDEX / Google Scholar / Crossref / Academic Keys I ROAD Open Access I OAJI / Academic Resources / Scientific Indexing Services / SCIPIO / JIFACTOR
\end{abstract}

pumps for lifting during functioning and correct oil flow); no other active alarm; at least two diesel generators connected to the network in case the main bus is closed; auxiliary installation sequence running (up to 20 seconds); speed indicator at 0 rpm.

When the emergency diesel generator is connected to the network, the propulsion engine is shut off. The propulsion transformers remain under tension, the circuit breakers are closed.

The propulsion engine is ready for restarting when two diesel generators are connected in the network, the reference speed is $0 \mathrm{rpm}$, the "Reset" and "On" buttons are pressed, the reference speed is increasing.

\section{The propulsion installation operating} procedure

When the test mode is On:

- the reference speed of the propulsion engine will be limited to $20 \%$ of its nominal value;

- the reference speed will be limited to $20 \%$ of its nominal value even if the command room the lever is set to $100 \%$. The test mode may be selected/unselected by pushing the "Test Mode" button when the lever is brought back to the "Zero" position.

\section{The command and control of the reference} speed - figure 3 .

"Remote control" mode allows the propulsion engines to be controlled by one of the following places: wheel house, engine control room, as well as from the local control board. The reference speed can be set from the main remote control system, from the lever on the console in the wheel house, from the lever on the port or starboard wing console, autopilot console in the wheel house, joystick in the wheel house, lever in ECR. Local, the reference speed can be set through the emitter of the engine control point.

The characteristics of the signals Reference Speed is sent from the remote control board to the PEC through the Ethernet network. In case of Ethernet network failure, a reference speed cable is connected to the wheel house, to the consoles on the wings and in ECR - all these location being connected in the control room and sent to PEC. Therefore, for an analogical signal we have:

- 4...20 mA from the Wheel house and the Control Point of the engine, $4 \mathrm{~mA}$ corresponding to 97 $\mathrm{rpm}$ ( $72 \%$ of the nominal revolution) and $20 \mathrm{~mA}$ corresponding to $150 \mathrm{rpm}$ (111\% of the nominal revolution)

The reference speed from the speed pilot set by joystick is sent to PEC through Ethernet. The emitter is situated in the engine control point. This transmitter is equipped with a $4 \ldots 20 \mathrm{~mA}$ transducer. Each $\mathrm{PEC}$ requires this signal for local control. We have 4...20 mA coming from transducer, $4 \mathrm{~mA}$ corresponding to $97 \mathrm{rpm}$ (72\% of the nominal revolution) and $20 \mathrm{~mA}$ corresponding to $150 \mathrm{rpm}$ (111\% of the nominal revolution)

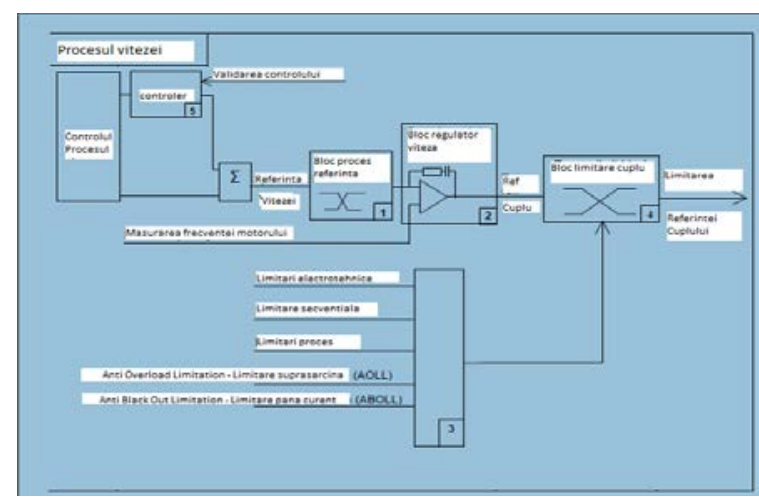

Figure 3.

Figure 4 represents the way of controlling the speed in order to generate a reference for the couple. For this, PEC has the following functions:

- when working at the reference speed the gradient generation represents the acceleration and deceleration process;

- speed regulator: adjusting between the measurement of the engine's frequency and the reference speed through an reference adjustment of the couple;

- couple limitation

The Fast Mode is used in order to obtain high performance in ships when having at least three diesel generator connected in the network - figure 4.

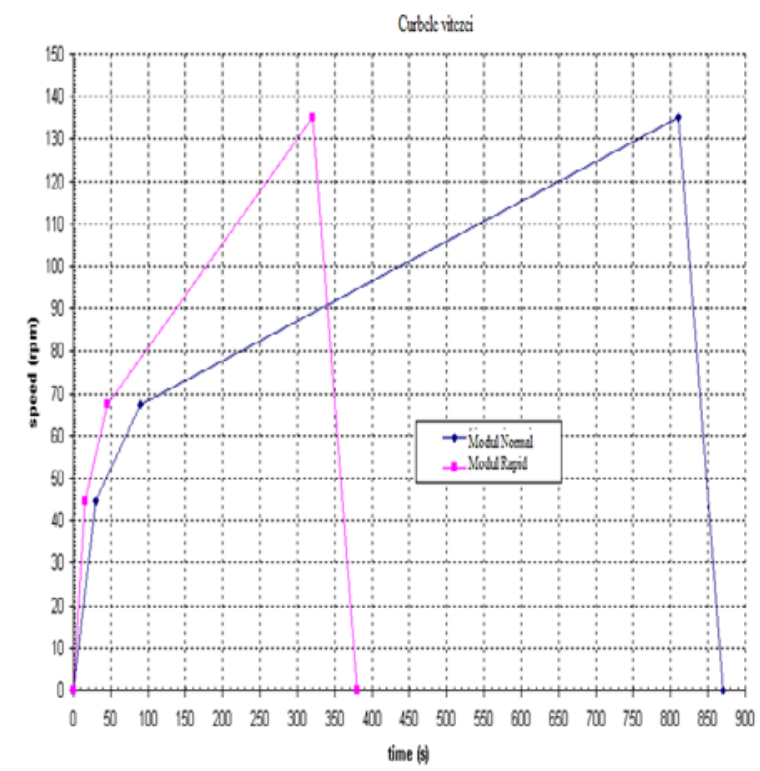

Figure 4.

The rate control consists of:

- the possibility to select "Normal Mode" by pressing the "Speed Slope Changing" button from the wheel house console, wings consoles. This selection depends on the number of the 


\begin{abstract}
"Mircea cel Batran" Naval Academy Scientific Bulletin, Volume XX - 2017 - Issue 1
Published by "Mircea cel Batran" Naval Academy Press, Romania /I The journal is indexed in: PROQUEST I DOAJ / DRJI / JOURNAL INDEX / I2OR / SCIENCE LIBRARY INDEX / Google Scholar / Crossref / Academic Keys I ROAD Open Access / OAJI / Academic Resources / Scientific Indexing Services / SCIPIO / JIFACTOR
\end{abstract}

generators connected in the network. The "Normal Mode" is selected automatically if the command is passed from ECR to the wheel house (no matter how many generators are connected in the network). The "Auto Mode" is automatically activated is there are less than three generators connected in the network. The "Rapid Mode" is selected if there are three or more generators connected in the network.

Couple limiting - in conformity with the design of each part of the propulsion system, some couple limitations are provided, even if the couple is positive (propulsion mode) or negative.

\section{Limitations}

4.1. Electro technical limitations - For taking in consideration the converter's capacity, there is a limitation given corresponding with the engine's speed, therefore $50 \%$ of the nominal couple lower than $15 \mathrm{rpm}$ (11\% of the nominal frequency), proportional limitation between 15 and $60 \mathrm{rpm}$ (44\% of the nominal frequency) and from $50 \%$ to $100 \%$ of the nominal couple. This is limiting the couple in low speed intervals in order to conform to the converters' design and, with the nominal speed, to maintain the propulsion engine's power constant (up to $105 \%$ of the nominal frequency). In the "Half Engine Mode" there is a limitation keeping the delivery couple below $50 \%$ of the nominal value. The same electro technical limits are applied in the case that the couple is inverted.

4.2 Sequential limitation - In case of overheating, for example of the propulsion's oil transformer, the couple has to be limited in order to avoid any other overheating of elements, that is why two current limitation thresholds are provided (66\% and $33 \%$ of the nominal current). When a fault appears, these limitations are activated sequentially. The sum of these actual limitations on both engines leads to a limitation of the couple of the shaft. The value of these limitations is not dependent of the engine's speed.

4.3. The limitation of the couple due to the technical design of the shaft. For a direct couple of $40 \%$ of the nominal couple - $97 \mathrm{rpm}$ to the astern propulsion ( $72 \%$ of the nominal frequency) at $40.5 \mathrm{rpm}$ ahead propulsion (30\% of the nominal frequency) and $117.5 \mathrm{rpm}(87 \%$ of the nominal frequency), from $40 \%$ to $100 \%$ of the nominal couple. For the inverted couple at $97 \mathrm{rpm}$ ( $\sim 72 \%$ of the nominal frequency) - astern to full ahead.

4.4 Limitation system (PLS) - The electric propulsion is the main consumer of the vessel. For this reason, for preventing any blackout due to overcharging or undercharging of a generator there is a limitation system. The PLS function is always active, that is why when the vessel is berthed and the propulsion is stopped, if greater voltage than one generator can deliver is needed, the PLS function will ask for another generator.
4.5. Overcharge prevention AOLL- This function is managed by PEC and generates a limiting couple. In the main board is monitored the generator breakers' position, the bus breaker's position and the active and reactive power on each generator are measured. The PLS software is designed to allow the usage of the total capacity of the generator. The output value of the maximum active and reactive power of the generator is calculated according to the power capacity of it.

4.6. The limitation acts on the generator with the greatest charge. In the case of active overcharge power limitation (Pmax), when the request of active power for propulsion is greater than the maximum active power available in the network, the propulsion power is automatically limited. The Pmax threshold is personalized in accordance with the operator's request from the control system. The same in the case of reactive overcharge power limitation (Qmax). The calculation of the Qmax threshold is made in accordance with the power factor of the generator. 4.7 Under charge limitation - In the case of undercharge limitation of the active power (Pmin), during the reduction of the speed of the propulsion engine, during an accident-stop sequence, the service charge of each generator is maintained in a predetermined threshold of minimum active power through the propulsion system.

4.8 Anti black out limitation: $A B O L$ - In order to avoid any overcharge in case of a $\mathrm{I} / \mathrm{O}$ rack fault (I/O from the PLS board), there is an incorporated limitation system in each PEC which controls the propulsion engine. This limitation is activated as soon as the frequency or voltage in the network is not in the parameters. This function is performed by PEC in order to ensure the necessary reaction speed in which regards the converter.

4.9 Frequency limitation min / max - Powering frequency is permanently checked. In case its value falls below a certain level $(58.5 \mathrm{~Hz})$, this means that the generators are overcharged (active power). In order to prevent a black out, an automatic limitation of the couple on the propulsion engine is deployed. If the value of the powering frequency rises above a certain level (63 $\mathrm{Hz}$ ), it means that during a breaking operation of the shaft when the propulsion engine is in active mode, the generators are undercharged and they are going to increase their frequency (speed). For preventing a black out there is implemented an automatic limitation of the couple of the propulsion engine.

4.10 Limitation of the network's voltage The powering voltage is permanently checked. In the case its value falls below a certain level (0.85 UN) these means that the generators are overcharged (reactive power). In order to prevent a blackout 


\begin{abstract}
"Mircea cel Batran" Naval Academy Scientific Bulletin, Volume XX - 2017 - Issue 1
Published by "Mircea cel Batran" Naval Academy Press, Romania /I The journal is indexed in: PROQUEST I

DOAJ / DRJI / JOURNAL INDEX I I2OR / SCIENCE LIBRARY INDEX / Google Scholar / Crossref / Academic Keys I ROAD Open Access I OAJI / Academic Resources / Scientific Indexing Services / SCIPIO / JIFACTOR
\end{abstract}

there is implemented an automatic limitation of the

couple of the propulsion engine.

\title{
Conclusions
}

The propulsion is completely controlled and monitored by its own control system - PCS. The humanmachine interface is one of the main inputs of the PCS and it consists in multiple remote control stations positioned in different places onboard (wheel house, ECR, local) The control system is completely digital and performs all the propulsion related functions.

Each control unit is split in two parts dedicated for the control and monitoring of the engines and converters from the supply room. Each one comprises of a electronic power controller (EPC).

A principal CPU, standard VME (the Versa Module Europa is a standard computer bus, firstly developed for the Motorola $68000 \mathrm{CPUs}$, after that being widely used for several standardized applications). This board control, the VME, realizes the communication with other boards in the slots. This handles the reference speed and the high frequency couple (period $<1 \mathrm{~ms}$ ) and generates the point for setting the control (triggering angle) for the excitation of the PIB and the PIB converter. These sets of points are set to PIB by the transfer information board (TIB). TIB is a high and rapid electronic power connection interface.

The monitoring system has the following functions:

- Monitoring the electric propulsion of the vessel;

- Control alarm;

- $\quad$ Logbook. Recording of the tendencies of the recording chart;

- Time synchronization for the propulsion control system.

\section{Bibliography}

[1] Samoilescu,G. ş.a.,,Exploatarea Sistemelor Energetice Navale”, Constanţa, Editura Academiei Navale,, Mircea cel Batrân", 2004

[2] Nanu, D.,,Sisteme Electromagnetice Navale”, Constanţa, Editura Muntenia, 2004

[3] Bishop, G.N., s.a. ,Electric Propulsion of Surface Fighting Ships”, Proc. Of Eleventh Ship Control System Symposium, 1997

[4] Alf Kare Adnanes, ,Maritime Electrical Installations and Diesel Electrical Propusion”, Oslo ABB AS,Marine, 2003

[5] Gheorghiu, S. S.a „Maşini şi Sisteme de Acţionări Electrice Navale” Bucureşti, Editura Academiei Române, 2004

[6] Blokland, A.J. s.a. „Electric Ship Propulsion”, Proc. of EPE'95.6th European Conference on Power Electronics and Applications, 1995

[7]Horne, C.D., S.a ,,Naval Electric Power Control and Monitoring Systems - A View of the Future”, Proc. of Eleventh Ship Control Symposium, Aprilie 1997, UK.

[8] xxx „Manualul Ofiţerului Electrician”, Constanţa, Editura Muntenia, 1997

[9] Chen Yutao, Zeng Fanming, Wu Jiaming, Integrated Design Platform for Marine. Electric Propulsion System, 2012 International Conference

[10]xxx Veritas

[11] xxx Science et vie

[12] Xxx Lloyds Ships Manager

[13] XXX ABS

[14] XXx IEEE

[15] Xxx Canadian Maritime Industries

[16]xxx Documentaţie Companii Navale

[17] ***Internet www.marine.man.eu

[18] ***Internet www.abb.com

[19] ${ }^{* \star \star}$ www.marinetraffic.com [15.03.2016] 